\section{Grass Seedling Emergence and Survival from Furrows ${ }^{1}$}

\author{
A. C. HULL, JR.2
}

Range Scientist, Crops Research Division, Agricultural Research Service, U.S. Department of Agriculture, Logan, Utah.

\section{Highlight}

Intermediate wheatgrass was seeded in 8 different furrow conditions for 5 years at $\mathbf{8 , 4 0 0}$ feet elevation and crested wheatgrass for 3 years at 4,800 feet elevation. At the high elevation best seedling emergence was from level and from 1- and 2-inch furrows. Plant survival was best from these 3 positions and from the bottom and north exposure of 4-inch furrows. The south exposure and ridge of 4-inch furrows were poorest in plant survival. At the lower elevation, plant emergence and survival were the best on the level, 1., 2-, and 4-inch furrows and poorest on the ridge and north and south exposures. In an earlier study $\mathbf{. 3 6}$ plants/foot of drill row emerged and .07 survived in 4-inch furrows. On the ridge between, 1.62 plants/ft emerged and .22 survived. In these studies, the deep furrows were no better for seedling emergence than shallow furrows and the level.

Seeding in deep furrows has been recommended to improve seeding success (Plummer et al., 1955; Hull and Holmgren, 1964). McGinnies (1959) found that 2-, 3-, and 4-inch furrow depths increased soil moisture, and that 4-inch furrow depths improved seedling establishment. Shaw and Buchele (1957) reported soil temperatures of $75 \mathrm{~F}$ at 1 inch in 10 -inch furrows while the ridge between was $82 \mathrm{~F}$. On a semi-desert habitat in Arizona, Cable (1969) found the maximum temperature to be $141 \mathrm{~F}$ at the .5 -inch soil depth. Geiger (1957) states that the highest temperatures are at the ground level, and that temperatures decrease going either upward or downward. He further states that the soil surface in temperate zones commonly reaches $158 \mathrm{~F}$ and that temperatures of $176 \mathrm{~F}$ can be expected on southern exposures. Laude (1957) reported that soil temperatures of $121 \mathrm{~F}$ during pre-emergence reduced emergence of annual grasses by $90 \%$ and that $122 \mathrm{~F}$ stopped all emergence. Laude et al. (1952) also found that preemergent temperatures which reduced seedling

\footnotetext{
${ }^{1}$ Cooperative investigations of Crops Research Division, Agricultural Research Service, U.S. Department of Agriculture; U.S. Forest Service, U.S. Department of Agriculture; and Utah Agricultural Experiment Station. Utah Agricultural Experiment Station Journal Paper 907. Received November 8, 1969; accepted for publication January 20, 1970.

2 The author thanks those who assisted with the field phases of the study, and those who made helpful comments on the manuscript. He is particularly grateful to Steven Smith and Arvel T. Bitters, who did much of the field work, and to E. James Koch, who made the statistical analyses.
}

emergence of perennial grasses by $90 \%$ varied from $117 \mathrm{~F}$ for harding grass to $125 \mathrm{~F}$ for nodding stipa.

Past studies at the present seeding site showed low emergence and high death loss of smooth brome and intermediate wheatgrass seedlings (Hull, 1966). Studies were initiated to determine soil temperatures and moisture at different positions in furrows and to find which positions were best for emergence and survival of seedlings of range grasses.

\section{Experimental Seedings}

Two studies were at Franklin Basin, Franklin County, in southeastern Idaho. This experimental site is located in a weedy opening in the spruce-fir type. The dominant vegetation is tarweed (Madia glomerata Hook.). The soil is clay loam with a $\mathrm{pH}$ of 5.7. The soil is low in organic matter, and it compacts and hardens quickly after snow melt. Elevation is 8,400 feet and the slope is $3 \%$ west. Annual precipitation averages 47 inches with 7 inches from June through September. Snow usually covers the area from early November to early June. Water-trapping cans were used to measure the height of flood water in furrows during spring snow melt.

In the first study we made furrows 4 inches deep, 24 inches apart and 25 feet long on the contour, which was approximately north and south. There were 5 furrows per plot with 4 replications in each of 3 years (1957-59). Twenty-five seeds per foot of row were drilled with a belt seeder at approximately .75 inch deep in the furrow and on the ridge betwcen furrows (Fig. 1).

In the second study we placed 50 seeds approximately 1 inch apart and .75 inch deep at each of 7 seed placements in furrows which were at right angles to the sun's rays at 1:00 p.m.: level; 1-, 2- and 4-inch furrows; north and south exposures of 4-inch furrows; and ridges between 4-inch furrows. An additional 4-inch furrow placement was parallel to the sun's rays. Furrows were 4.2 feet long and 1 foot apart. This study was also repeated near Logan, Utah. This is a bench area at 4,800 feet elevation which slopes $1 \%$ to the west. Annual precipitation is about 17 inches. The soil is a deep, productive Timpanogas silt loam.

In the second study we seeded five replicate blocks to intermediate wheatgrass (Agropyron intermedium (Host) Beauv.) each spring for 5 years (1962-66) at Franklin Basin and to crested wheatgrass (A. desertorum (Fisch.) Schult.) for 3 years (1964-66) at Logan. Intermediate wheatgrass had $90 \%$ germination and crested wheatgrass $92 \%$.

Seedlings emergence was counted and marked weekly with colored wire pins. Survival was determined each fall for 2 years following seeding. Significance of plant numbers at $5 \%$ level was determined by Duncan's (1955) multiple range test.

In the second study we determined summer soil moisture weekly with gypsum blocks at $.75,3,6$, and 12 inches under the various seed placements. There was also some gravimetric soil sampling at Franklin Basin. All moisture determinations commenced as soon after snow melt as feasible and continued through late fall.

In the second study, soil temperatures at .75 inch for some seed placements were recorded for all years with multiple pen thermographs. Soil temperatures at the surface, .75, 3,6 and 12 inches for most seed placements were determined by reading thermistor units weekly at 1 p.m. Temperature 

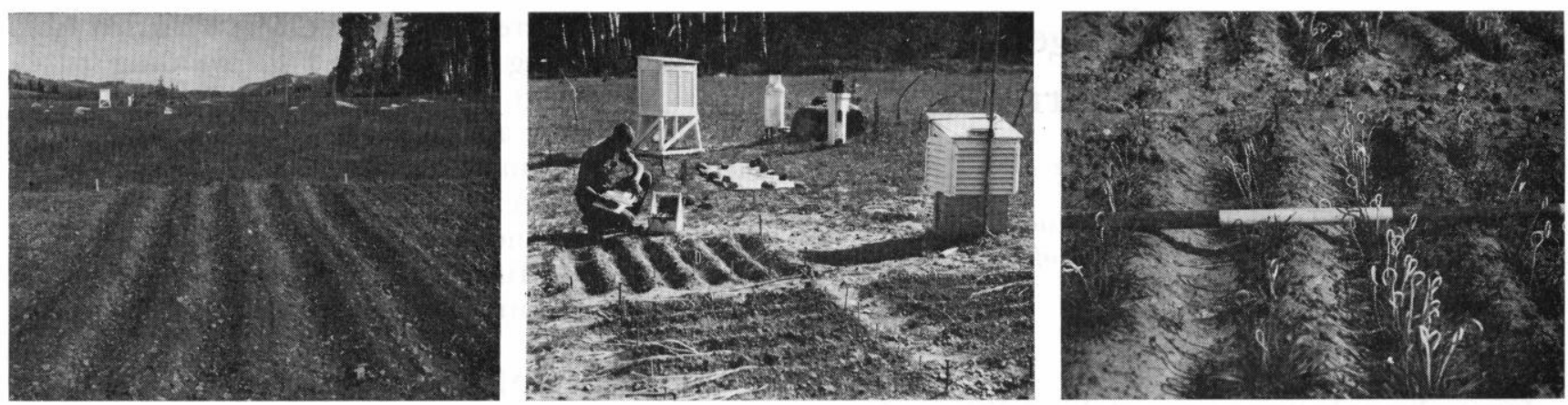

Fig. 1. Furrows at Franklin Basin. (left) Furrows in the 1957-59 study are 4 inches deep and 24 inches apart. (center) In the 1962-66 study, furrows in the foreground are at right angles to the sun's rays at 1 p.m., those in the background are parallel. (right) Left to right: Ridge, north exposure, 4-inch furrow, and south exposure. Seeded May 1, 1966. Wire pins mark the emerged seedlings, $20 \%$ of which were dead by August 10 when photo was taken.

pellets were used for soil surface temperatures at Franklin Basin (Silen, 1956).

\section{Results and Discussion}

Averaging all 3 years in the first study, .36 plants $/ \mathrm{ft}^{2}$ emerged in the furrows and .07 were alive at the end of 2 years. On the ridge 1.62 plants emerged and .22 survived. In the second study there were some inconsistencies in emergence and survival among treatments and years. The average is shown in Table 1.

There was high mortality of seedlings at Franklin Basin. Most death loss occurred either from drought during the first summer or from frost heaving the first fall or the next spring. On the ridge and the south exposure, mortality from the two causes appeared about equal. On other placements, frost heaving caused the most death loss. At Logan only the 1966 seedlings died from frost heaving.

Precipitation during the summer following seeding in 1962 was near normal and there was good seedling emergence and fair survival. The years

Table 1. Percent emergence and second year survival of intermediate wheatgrass plants from 8 different seed placements. Average of 5 years (1962-66) at Franklin Basin and 3 years (1964-66) at Logan.

\begin{tabular}{llllll}
\hline \hline \multirow{2}{*}{$\begin{array}{c}\text { Seed } \\
\text { placements }\end{array}$} & \multicolumn{2}{c}{ Franklin } & Basin & & \multicolumn{2}{c}{ Logan } \\
\cline { 2 - 3 } \cline { 5 - 6 } \cline { 5 - 6 } & Emerg. & Surv. & & Emerg. & Surv. \\
\hline Level & $35 \mathrm{a}^{*}$ & $6.7 \mathrm{ab}$ & & $54 \mathrm{a}$ & $19 \mathrm{a}$ \\
l" furrow $^{\prime \prime}$ & $37 \mathrm{a}$ & $6.6 \mathrm{ab}$ & & $54 \mathrm{a}$ & $19 \mathrm{a}$ \\
$2^{\prime \prime}$ furrow & $35 \mathrm{a}$ & $6.6 \mathrm{ab}$ & & $52 \mathrm{a}$ & $17 \mathrm{ab}$ \\
$4^{\prime \prime}$ furrow & $30 \mathrm{~b}$ & $8.0 \mathrm{a}$ & & $53 \mathrm{a}$ & $18 \mathrm{a}$ \\
$4^{\prime \prime}$ furrow P** & $26 \mathrm{c}$ & $4.9 \mathrm{abc}$ & & $55 \mathrm{a}$ & $18 \mathrm{a}$ \\
North exposure & $23 \mathrm{~cd}$ & $7.3 \mathrm{a}$ & & $40 \mathrm{~b}$ & $13 \mathrm{~b}$ \\
South exposure & $19 \mathrm{~d}$ & $3.8 \mathrm{bc}$ & & $38 \mathrm{~b}$ & $8 \mathrm{c}$ \\
Ridge & $19 \mathrm{~d}$ & $3.0 \mathrm{c}$ & & $25 \mathrm{c}$ & $8 \mathrm{c}$ \\
\hline
\end{tabular}

* Any 2 means followed by the same letter are not significantly different at the $5 \%$ level.

** Parallel to sun's rays at 1:00 p.m. All others at right angles.
1963 and 1964 were drier than normal with poor emergence and survival. Precipitation during 1965 was far above normal, with good seedling emergence and survival. Precipitation during 1966 was below normal, but there was good emergence and fair survival.

The summer of 1964 with poor stands and 1966 with excellent stands had similar precipitation. In 1964 snow melted on June 8, but wet soil prevented planting until June 29. By July 20 the soil was hard. Though many seeds germinated, only a few seedlings managed to emerge between July 23 and August 3. In 1966 snow left on May 13, seedings were made on May 21, seedlings emerged June 3 to 20 and plants were well established before the summer dry period. In 1965 snow melted on June 14 and seedlings were made June 21, even later than in 1966; but, because of a wet summer, stands were as good as in 1966.

Soil moisture readings varied greatly between placements at the .75 and 3 inch soil depths with little difference at 6 and 12 inches. However, as seeds must germinate and send out roots and shoots at shallow depths, moisture at shallow depths is critical in seedling emergence and survival.

Soil moisture was generally best in deep furrows, next in the shallow furrows and the north exposure and poorest in the ridge, south exposure and level. Soil moisture at .75 inch in the deep furrows at Franklin Basin reached wilting for 5 short periods during the 5 summers. On the level it averaged below wilting one-fourth of the time and on the ridge one-third of the time. It is not feasible to show soil moisture data at all seed placements, depths, seasons, locations, and years. Therefore, this is typified by 1962 soil moisture stress readings at Franklin Basin at 2 depths under the furrow and under the ridge (Table 2). There was little moisture stress at 6 inches under any placement and none at 12 inches.

Soil temperatures varied with placement, depth, season, and from day to night (Table 3). An exam- 
Table 2. Weekly rainfall (inches) and bars of suction measured by gypsum blocks at 3/4- and 3-inch depths under 4-inch furrows and under the ridge between furrows at Franklin Basin, 1962.

\begin{tabular}{|c|c|c|c|c|c|c|}
\hline \multirow{2}{*}{$\begin{array}{c}\text { Dates } \\
\text { mea- } \\
\text { sured }\end{array}$} & \multirow{2}{*}{$\begin{array}{c}\text { Rain- } \\
\text { fall }\end{array}$} & \multicolumn{2}{|c|}{ 4-inch furrow } & \multicolumn{2}{|c|}{$\begin{array}{l}\text { Ridge between } \\
\text { furrows }\end{array}$} & \multirow[b]{2}{*}{$\Lambda \mathrm{vg}$. } \\
\hline & & $3 / 4$ & 3 & $3 / 4$ & 3 & \\
\hline June 11 & 0.3 & 0.5 & 0.4 & 3.0 & 0.6 & 1.1 \\
\hline June 18 & 0.2 & 0.5 & 0.4 & 2.0 & 0.8 & 0.9 \\
\hline June 25 & 0.2 & 1.4 & 2.4 & 6.8 & 3.9 & 0.6 \\
\hline July 2 & 0.1 & 5.0 & 0.5 & 7.9 & 5.3 & 4.7 \\
\hline July 9 & 0 & 14.8 & 0.8 & 15.0 & 15.0 & 11.4 \\
\hline July 16 & 1.4 & 0.5 & 0.3 & 1.0 & 0.5 & 0.6 \\
\hline July 23 & 0 & 1.9 & 0.4 & 15.0 & 5.6 & 5.7 \\
\hline July 30 & 0.5 & 0.9 & 0.3 & 4.1 & 1.3 & 1.7 \\
\hline August 6 & 0.3 & 0.6 & 0.4 & 0.9 & 0.5 & 0.6 \\
\hline August 13 & 0.7 & 1.0 & 0.4 & 6.0 & 3.2 & 2.7 \\
\hline August 20 & 0 & 6.5 & 1.0 & 10.9 & 7.4 & 6.5 \\
\hline August 27 & 0 & 11.5 & 1.8 & 15.0 & 14.6 & 10.7 \\
\hline September 3 & 0 & 14.5 & 3.6 & 15.0 & 15.0 & 12.0 \\
\hline September 10 & 0 & 15.0 & 5.4 & 15.0 & 15.0 & 12.6 \\
\hline Avg. & & 5.3 & 1.3 & 8.4 & 6.3 & \\
\hline
\end{tabular}

ple of temperature differences at .75 inch among some seed placements and also of the diurnal fluctuation for one day is July 10, one of the hottest days in 1962 at Franklin Basin (Fig. 2). Differences in soil temperature under the different seed placements lessened with depth, but even at 6 inches below the surface, the average maximum soil tem-

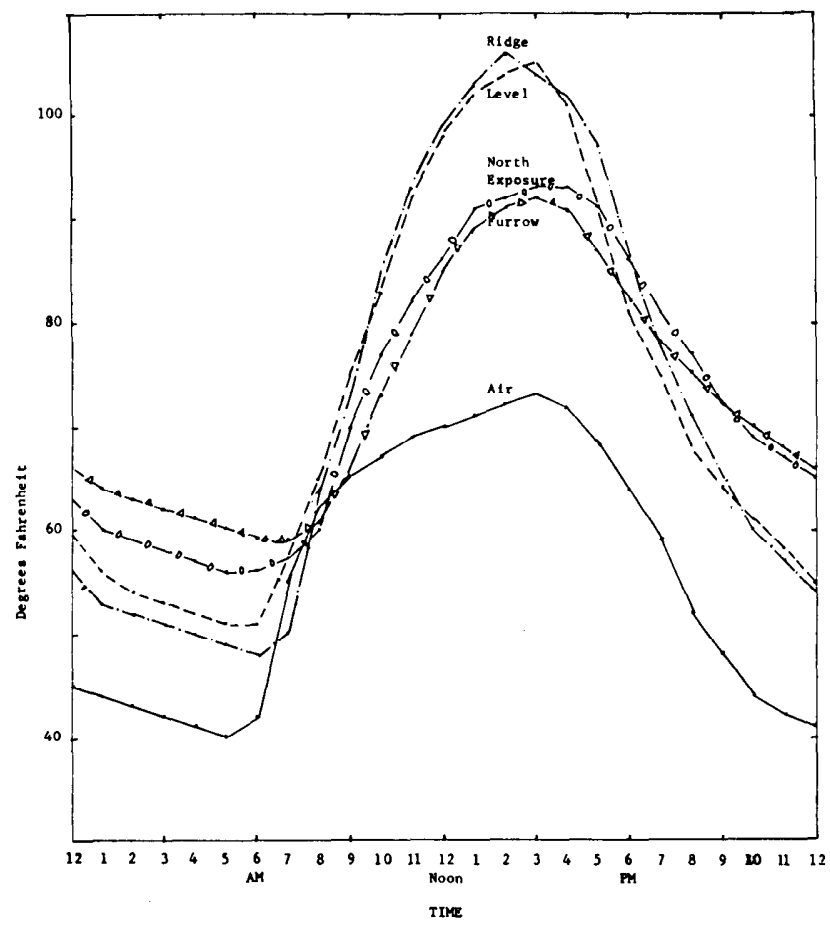

Fig. 2. Air and .75 inch soil temperatures in degrees $F$ from thermograph bulbs under different seed placements on July 10, one of the warmest days in 1962 at Franklin Basin.
Table 3. Average of the highest weekly maximum and the lowest minimum soil temperatures at 0.75 inch in degrees $F$ for different seed placements from early spring through August and air temperature. Average of 5 years (1962-66) at Franklin Basin and 3 years (1964-66) at Logan.

\begin{tabular}{|c|c|c|c|c|}
\hline \multirow{2}{*}{$\begin{array}{c}\text { Seed } \\
\text { placement }\end{array}$} & \multicolumn{2}{|c|}{ Franklin Basin } & \multicolumn{2}{|c|}{ Logan } \\
\hline & Max. & Min. & Max. & Min. \\
\hline \multicolumn{5}{|c|}{ Soil temperature } \\
\hline Level & 99 & 43 & 112 & 49 \\
\hline 2" furrow & 92 & 42 & $*$ & * \\
\hline $4^{\prime \prime}$ furrow & 90 & 49 & 100 & 52 \\
\hline North exposure & 92 & 48 & 103 & 52 \\
\hline South exposure & 96 & 40 & $*$ & $*$ \\
\hline Ridge & 98 & 40 & 113 & 43 \\
\hline \multicolumn{5}{|c|}{ Air temperature } \\
\hline & 76 & 32 & 89 & 41 \\
\hline
\end{tabular}

* No data

perature was 3 to $9 \mathrm{~F}$ higher under the ridge than under the furrow.

The hottest .75 inch soil temperature during the study was $108 \mathrm{~F}$ on the level at Franklin Basin and $135 \mathrm{~F}$ at Logan. Temperature pellets showed the surface soil to be 10 to $20 \mathrm{~F}$ higher than the .75 inch soil temperatures. These high temperatures, combined with drought, killed newly emerged 1to 2-leaf seedlings on both areas, but especially at Franklin Basin. Vigorous 3- to 5-leaved plants often dried and became dormant but were seldom killed.

During spring snow melt, water reached a depth of 1.5 inches in 2 of the 3 years and .5 inch in the other year in the first study (1957-59). Standing water in early spring was undoubtedly a major factor in the significantly decreased emergence and survival in the furrow as compared to the ridge. Water was never .5 inch deep in the second study. Observations on other studies at Franklin Basin and at other high elevation areas show that flood water in early spring often kills seedlings. ${ }^{3}$

\section{Conclusions}

Under the conditions of these studies, seedings in deep furrows, shallow furrows, north exposures and the level were superior to those on the south exposure and the ridge.

\section{Literature Cited}

Cable, Dwight R. 1969. Soil temperature variations on a semidesert habitat in southern Arizona. U.S. Forest Serv. Res. Note RM-128, 4 p.

Duncan, David B. 1955. Multiple range and multiple F tests. Biometrics 11:1-42.

Geiger, Rudolf. 1957. The climate near the ground. Harvard Univ. Press, 494 p.

3 Personal communication from A. T. Bleak. 
Hull, A. C., JR., and Ralph C. Holmgren. 1964. Seeding southern Idaho rangelands. U.S. Forest Serv. Res. Paper INT-10, $32 \mathrm{p}$.

Hull, A. C., JR. 1966. Emergence and survival of intermediate wheatgrass and smooth brome seeded on a mountainous range. J. Range Manage. 19:279-283.

Laude, Horton M. 1957. Comparative pre-emergence heat tolerance of some seeded grasses and of weeds. Bot. Gaz. 119:44-46.

Laude, Horton M., Jeffrey E. Shrum, Jr., and Wayne E. BieHLer. 1952. The effect of high soil temperatures on the seedling emergence of perennial grasses. Agron. J. $44: 110-112$.
MaGinnies, William J. 1959. The relationship of furrow depth to moisture content of soil and to seeding establishment on a range soil. Agron. J. 51:13-14.

Plummer, A. Perry, A. C. Hull, Jr., George Stewart, and Joseph H. Robertson. 1955. Seeding rangelands in Utah, Nevada, southern Idaho, and western Wyoming. U.S. Dep. Agr. Handbook 71, 73 p.

Shaw, Robert H., and Wesley F. Buchele. 1957. The effect of the shape of the soil surface profile on soil temperature and moisturc. Iowa Statc College J. Sci., 32: 95-104.

Silen, Roy R. 1956. Use of temperature pellets in regeneration research. J. Forestry, 54:311-314. 